\title{
STUDY THE CAUSE OF DEATH \& ITS SOME FACTORS AMONG HOSPITALIZED PAEDIATRIC CASES AT A TERTIARY CARE CENTRE OF RURAL DISTRICT OF MAHARASHTRA, INDIA.
}

Amol R. Patili ${ }^{1}$, Anant N. Borde 2

\section{HOW TO CITE THIS ARTICLE:}

Amol R. Patil, Anant N. Borde. "Study the Cause of Death \& its some factors among Hospitalized Paediatric Cases at a Tertiary Care Centre of Rural District Of Maharashtra, India". Journal of Evolution of Medical and Dental Sciences 2014; Vol. 3, Issue 02, January 13; Page: 313-321, DOI:10.14260/jemds/2014/1827

ABSTRACT: BACKGROUND: Reaching the MDG on reducing child mortality will require universal coverage with key effective and affordable interventions. Records of vital events like death constitute an important component of public health information system. In-depth analysis of death of children provides valuable information. Aim of the study was to describe the causes of deaths among hospitalized pediatric patient and contributing factors associated with it. METHODS AND MATERIALS: This was a retrospective record based study. Total pediatric deaths were identified \& segregated through admission records from medical record section under PSM department of Government Medical College, during January 2010 to December 2010. Variables like age, sex, birth weight and cause of death were collected from death records. WHO Child Growth Standards (z score) separate for boys \& girls were used for comparing weight of child at the time of admission. Data was entered, cleaned and analyzed using MS excel. RESULTS: An overall 313 (13.1\%) death occurred among 2380 hospitalized pediatric cases.56.4\% were male child and $43.8 \%$ female child. Maximum deaths (67.8\%) were among early neonates. $175(60 \%)$ were severely underweight at the time of admission. Time interval between admission and death i.e. hospital stay revealed that 134 $(42.8 \%)$ of deaths occurred within $24 \mathrm{~h}$ of admission. 180 (77\%) deaths were in low birth weight (less than $2.5 \mathrm{~kg}$ ). Infection (35\%) was the leading cause of death among all pediatric age groups followed by birth asphyxia (29\%), prematurity (22\%) nutritional (4\%) and congenital (6\%).Viral encephalitis was found to be the most common cause of death in more than 5 yrs. age group. CONCLUSION: Monitoring the mortality pattern among hospitalized cases is important strategy to address public health issues at community level as well as to strengthen the hospital services. Strategies like antenatal care about nutrition to avoid LBW, timely treatment of complications for newborns(NSSK), integrated management of neonatal \& childhood illness for all children under five years, immunization; infant and young child feeding(IYCF) should be strengthened effectively at community level to reach the MDG on reducing child mortality along with the higher level NICU set up specially at under resource tertiary care centre to prevent neonatal death.

KEY WORDS: Hospitalized, Pediatrics, Cause of death, factors, Rural.

INTRODUCTION: One of the Millennium Development Goals (MDG-4) was to reduce the child mortality rate (under 5 years) by two-thirds by the year 2015 from a baseline in 1990. As per global under five mortality trend, 1980-2010 there is still gap in achieving MDG-4 by year 20151.7.6 million Children under five years died in 2010. Over 70 percent of the world's under-five year children deaths in 2010 occurred in only 15 countries, and about half in only five countries and India is one of them $^{2}$. Infant Mortality Rate in India is steadily decreasing; currently estimated at 57 deaths before 
the age of 1 yr. per 1000 live births down from NFHS-2 estimates of 68 \& NFHS-1estimates of $79^{3}$. Sample Registration System (SRS) 2009 states U5MR declined by 54 points in last 20yrs that means annual average decline of 1.5 points. However more than 1 in 18 children still die within $1^{\text {st }}$ year of life $\& 1$ in 13 die before age of five in India 3 .

The relatively high levels of maternal and child mortality and morbidity compounded with a rapid growth in population adversely affected the social and economic developments in the developing countries ${ }^{4}$. Records of vital events like death constitute an important component of the Health Information System ${ }^{5}$. The assessment of deaths by cause provides a useful starting point for stocktaking of available child survival intervention ${ }^{6}$.

All countries need sound epidemiological information to prioritize, plan and implement public health interventions. Vital event registration that includes cause of death is used to establish cause structure of mortality 7 . Hospital based data about mortality provides information about death cause as well as in-depth analysis shows direct or indirect factors related to the death. This information helps the administration to see the pattern of deaths and interventions needed to control it at hospital level. The present study was aimed to describe the causes of deaths among hospitalized pediatric patients and factors associated with it.

MATERIAL \& METHODS: The present study was performed at Government Medical College, Dhule Maharashtra which is situated in rural area with a total of 545 beds in hospital. This was retrospective record based study. All the case records of hospitalized patients was collected \& stored at medical record section under PSM department. Case records of admitted patients in pediatric ward (age group up to 14 yrs.) during the period of January 2010 to December 2010 were collected from record section. Pediatric cases admitted in other than pediatric ward like burn ward, surgery ward, orthopedic ward were not included.

From the admitted case records of pediatric ward death case records were identified \& selected for study purpose. A retrospective descriptive study conducted with record of deaths that occurred in pediatric ward. Institutional ethical committee approval was obtained from institution for utilizing the hospital records.

For study purpose, data extracted from case record included variables such as age, sex, birth weight, address, weight at the time of admission, duration of hospital stay and cause of death whichwere recorded in a predesigned format. The underlying cause of death as documented with case records and certified by treating pediatrician was considered as the final cause of death. Case records without cause of death certificate were not included in study. WHO Child Growth Standards (z score) Charts ${ }^{8}$ separate for boys \& girls were used to compare the weight at the time of admission of death cases.

The data were entered, cleaned and analyzed in Microsoft ${ }^{\mathrm{TM}}$ Excel ${ }^{\circledR}$ 2010. Frequency distributions showing number and percentages were generated for each identified outcome variables.

RESULTS: A total of 2380 children comprising of 1328 (55.8/\%) male child and 1055 (44.2\%) female child were admitted into the Pediatric department during the study period. Out of total admissions, 5 years-14yrs of age group had 793(33.3\%) admissions in which $11(1.4 \%)$ cases died, followed by the early neonates age group which had 671(28.2\%)admissions inwhich $212(31.6 \%)$ 
cases died while 67(2.8\%) admissions of late neonates in which 21(31.4\%)cases died. For the age group >1month to 1year \&>1year to 5 years had $316(13.3 \%) \& 533(22.4 \%)$ admissions respectively in which $39(12.3 \%) \& 30(5.6 \%)$ cases died during the study period. Maximum admissions (964, $40.5 \%$ ) were seen during rainy season.

An overall 313 (13.1\%) death observed among hospitalized pediatric cases. Out of 1587 admission of less than 5 yrs. age group 19\% of deaths occurred as compared to $1.4 \%$ of deaths among 793 admissions of more than 5years to 12 years of age group. Proportionally more number of male child deaths were observed as compared to female child for all groups except the 1 month to 1 year i.e. female child (53.8\%) died more than male child (46.2\%).

Out of 313 deaths, 176(56.4\%) were male child and 137(43.8\%) female child.195 (62.3\%) death cases were from rural area. Maximum deaths (37.7\%) were observed during winter season after analyzing the season-wise distribution of deaths. $53.4 \%$ of death cases were amongst $1^{\text {st }}$ by order of birth. Age group wise distribution showed $67.8 \%$ of total death cases were from early neonatal period. Weight for age at the time of admission was noted among the 292 (93.3\%) death case records. Weight at the time of admission showed that 175(60\%) were severely underweight. Time interval between admission and death i.e. hospital stay revealed that 134 (42.8\%) of deaths occurred within $24 \mathrm{~h}$ of admission, 145(46.3\%) deaths occurred from 1-3days. The mean hospital stay of the death cases is 1.46 days. Infection, 125(35\%) was the most common cause of death followed by birth asphyxia, 101(29\%) \& Prematurity, 76(22\%) among deaths that occurred during study period.(Table 1$)$.

272(87\%) infant deaths were observed. Among infant deaths 233 deaths (85.7\%) occurred in neonatal period out of which $212(91.0 \%)$ were early neonatal deaths. More male children (55\%) were severely underweight as compared to female children (45\%).

In the present study, 180 death case records have noted the birth weight of the child. Minimum birth weight found was $500 \mathrm{gm}$. to maximum of $3790 \mathrm{gm}$. Birth weight wise distribution of the death cases is shown in Graph 1.

Among infection as the cause of death, for under 5 years of age groups, Septicemia(42\%), Pneumonia(20\%), HIV, TB \& Malaria(16\%), Viral Encephalitis (8\%), Measles \& Tetanus (8\%) contributed to cause of infection while for more than 5 years-12yrs age group children, viral encephalitis (36.4\%) was found to be a major cause of infection followed by retroviral disease(27.3\%) along with pneumonia(9\%) \& dengue(9\%).

Age group wise distribution of the cause of death is shown in Graph 2.Infection remains the most common cause amongst all age groups except in early neonates in which birth asphyxia and prematurity were most common cause. Nutritional cause is seen after infection among more than 1 year to less than $5 y$ rs of age group children.

DISCUSSION: In the present study, more number of male child than female child admissions isrelated to the biological vulnerability of males to infections or gender bias in case of accessing health care. The male child predominance of admission has been documented in various other studies.5, 9, 10 More than 65\% of admission load of under 5 years age group children shows vulnerability of this age group for contracting diseases or getting morbid as compare to more than 5yrs to 12 yrs. age group. Maximum admissions during rainy season showing rainy season encourages environmental factors (breeding of mosquito, contamination of drinking water source, 
humidity) for microorganism leads to infectious diseases. I.O. George et al ${ }^{11}$ stated the same findings in their study.

The study shows overall mortality $13.1 \%$, which was higher than that observed by Rabindra Nath et al ${ }^{12}$ at tertiary care hospital $(9.7 \%)$ at Kolkata. \& $2.7 \%$ observed at tertiary care centre, Chandigarh by Singhi $\mathrm{M}^{13}$. Higher mortality may be due to inclusion of neonatal deaths in the study as well as referral of high risk cases from rural and tribal areas. One of the reasons could be that the tertiary care centrehas been set up at under resource setting especially in relation to the neonatal care as also observed by the M.Hoque et al ${ }^{10}$ in their study at rural hospital in South Africa. 19\% of death of under five year children of the total admissions as compared to $1.4 \%$ death of more than 5 years-12 yrs. of children of total admission proves the more susceptibility of under 5 years age group for mortality and more concern or specialized care to these group is needed ${ }^{11}$.

There is 2.5 fold \& 5 fold increased chance of death among admitted cases for neonatal age group as compared to post neonatal age group \& between "1year to 5years age group" respectively. For only $2.8 \%$ of total admissions of late neonate, $31.4 \%$ of died. Less number of admissions may be due to non-availability of sufficient beds for neonatal admissions.

Overall male children had more proportion of deaths as compared to female children. This may be because more number of male child admissions. Also all age group wise male children had more percentage of death except from 1 month to 1year age group where female child is at more risk. This may indicate more negligence or non-acceptance of female child care after delivery especially in this study area. Claeson $\mathrm{M}$ et al ${ }^{14}$ estimated that a girl child in India is $30-50 \%$ more likely to die between her first and fifth birthday.

The proportion of deaths to admissions was higher in winter season, indicating the winter climatic conditions may be prone for acute respiratory infection especially young age group. I.O. George et al ${ }^{11}$ also observed more deaths during winter season. However, other studies ${ }^{5,12}$ indicate the lack of seasonal variability. More than $50 \%$ deaths were of $1^{\text {st }}$ borne. As the order increases, mortality decreases. Dr. Anish S. et al ${ }^{5}$ found $60 \%$ deaths were firstborn. The highest mortality in the firstborn has been documented. ${ }^{15}$

The present study reported neonatal period (74.4\% of total deaths) contributed more for overall children mortality admitted in the hospital. This finding is more as compare to the Augustin T \& Bhatia D who revealed the $40 \%$ mortality ${ }^{16}$ while M.Hoque et al ${ }^{10}$ reported $20 \%$ risk of neonatal death. The ICMR Young Infant Study Group identified the first three days as the most hazardous period of life ${ }^{17}$.They observed that $3 / 4$ th of the neonatal deaths and $1 / 2$ of the infant deaths occurred in the early neonatal period. Referral of high risk neonates \& under resource setting in rural tertiary care centre contributes to more neonatal deaths.

More than $40 \%$ of pediatric deaths occurred within $24 \mathrm{~h}$ of admission, which could be attributed to delay in care-seeking or transportation of high risk cases at tertiary care centre. R.D. Wammanda and F.U. Ali also reported the $40.1 \%$ death within $24 \mathrm{~h}$ of admission and reported cause was delay in commencement of treatmen ${ }^{18}$. Rabindra Nath Roy reported 55\% death within 24 hrs. Also more number of deaths within 1-3 days of hospitalization suggests lack of sophisticated NICU set up to manage critically ill neonates even after admission.

Marta Botrán Prieto \& Jesús López found that the presence of malnutrition prior to admission worsens the prognosis as well as interferes with the appropriate response of the body to the disease and predisposes to infection and to the onset of multiorgan failure, increasing morbidity 
and mortality. Malnutrition is common at the time of hospital admissions. The incidence of malnutrition varies between $25 \%$ and $70 \%$ in the critically ill child ${ }^{19}$. In our study we found $60 \%$ were severely underweight at the time of admission indicating malnutrition is important cause for mortality and also reflects the lack of infant and young child feeding practices at community levels. Robert BE et al7analyzedten longitudinal community based studies of children younger than 5 years showed that being underweight conferred an additional risk of mortality from infectious diseases. In India NFHS-3 estimated $40 \%$ of less than three year children was underweight 3 .

In the present study, Birth weight records found that 77\% were Low Birth Weight while 37\% were VLBW i.e. less than $1.5 \mathrm{~kg}$. Babies born with VLBW have mortality over $50 \%$ in low resource setting countries ${ }^{10}$. The lack of nutritional care during pregnancy or utilization of services by pregnant mothers for ANC care leads to fetal malnutrition and manifested as a LBW. Involvement of ASHA's for ANC care for improving birth weight can be utilized. Babies with low birth weight required special care during first hrs. to days of life 5 .

Infection was the most common cause of death occurring among hospitalized children for all age group except for early neonate where causes were Birth asphyxia \& prematurity. Ragvendra Narayanan also found prematurity \& Birth asphyxia cause of death among neonates ${ }^{20}$. Singh M noted from hospital-based data that bacterial sepsis was a major cause of neonatal mortality in India ${ }^{13}$. Nutrition related cause of death is seen after infection. M. Hoque et al ${ }^{10}$ also reported birth asphyxia, prematurity, LBW \& neonatal infection as a leading cause of hospitalization and deaths among neonates.

In present study, among infection, Septicemia (42\%), Pneumonia (20\%) \& HIV-TB-Malaria (16\%) contributes for deaths for less than 5 yrs. child. Acute Respiratory Infection is the leading cause of death in young children worldwide. These findings are more or less similar with the other studies.11,12 We also found Viral encephalitis as a cause of death for less than five years children but most common cause of death followed by HIV AIDS, Pneumonia and dengue for more than 5yrs age group children. Ajit Rayamajhi et al ${ }^{21}$ demonstrated Acute Encephalitis Syndrome of suspected viral etiology has significantly i.e.3 times more likely to have bad outcome compared to bacterial, JE or malarial infections. Identification and optimized treatment for viral encephalitis should be priority to prevent mortality. IO George et al $^{12}$ found malignancies and HIV/AIDS were the predominant cause for above 5 years of age.

In Conclusion, higher level NICU set up especially at under resource tertiary care centre like ours to prevent neonatal death along with the quality health care to decrease mortality as lower as possible is strongly implemented. Reaching the MDG on reducing child mortality will require universal coverage with key effective, affordable interventions; Strategies like appropriate home based neonatal care by health care worker and timely treatment of complications for newborns; integrated management of childhood illness for all children under five years old for diseases like Pneumonia, Diarrhea, Sepsis, Malaria, HIV-AIDS., Immunization; Infant and Young Child Feeding(IYCF) along with national nutritional programs like ICDS to prevent malnutrition must be intensified at community level. These child health strategies are complemented by interventions for maternal health, in particular, nutrition during ANC \& skilled care during pregnancy and childbirth through cost effective programs like Navjat Shishu Suraksha Karyakram (NSSK).These interventions could reduce the number of deaths by more than half. 
Limitation of the study: Hospital Record Based Retrospective study. During the analysis of records, we observed that the data were incomplete or some entries were inadequate, which were excluded from our study. Maternal factors were not included in study.

ACKNOWLEDGEMENT: We express our sincere thanks to the Dr. S.S. Gupta sir, Dean of our institution for giving kind support and permission to carry out this study at institute. Special thanks to Mr. S.M. Sonawane and staff of medical record section for their whole hearted support \& cooperation for providing records without which study could not have been initiated.

\section{REFERENCES:}

1. Inter-Agency Child Mortality Estimation Group (WHO, UNICEF, World Bank, UNDP and Independent experts). Level and Trends in Child Mortality. Report 2011.

2. J.Kishore.National Health Programs of India, 8 $^{\text {th }}$ Edition. New Delhi. Century Publications; 2009.Reprint 2010.

3. International Institute for Population Sciences (IIPS) \& Macro international 2007.MOHFW, National family health survey (NFHS-3), 2005-06, India; Key Findings.Mumbai; IIPS.

4. Rajvir Bhalwar, Agrawal Sunil, Basannar Dashrath, Bhatnagar Anuj, Bhatti Vijay, Chatterji Kunal et al. Textbook of Public Health \& Community Medicine, Community Medicine AFMC, Pune in collaboration with WHO India;2009.Chapter10, National Health Profile.

5. Dr.AnishS., Dr.Ann Tinu Sam, Dr.Anupa Alex, Dr.Ashitha.N.Baby. Mortality pattern of hospitalized neonates in a tertiary care hospital in Ernakullum. IMA Kerala Medical Journal.2011May; 3:pg95-102.

6. Gareth Jones, Richard W Steketee, Robart E Black, Zulfiqar A Bhutta, Saul S Morris. How many child deaths can we prevent this year? The Lancet. 2003 July 5; Vol 362:65-71.

7. Robart E Black, Saul S Morris, Jennifer Bryce. Where and why are 10 million dying every year? The Lancet.2003 June 28; Vol 361:2226-34.

8. WHO Child Growth Standards; length/height for age, Weight for age, Weight for length, Weight for height \& Body Mass index-for-age: Methods \& development. A Technical Report; WHO.2006.

9. Singhi S, Gupta G, Jain V. Comparison of pediatric emergency patients in a tertiary carehospitalvs. a community hospital. Indian Pediatr. 2004; Vol 41: 67-72.

10. $M$ Hoque, $S$ Haaq, $R$ Islam. Causes of neonatal admissions and deaths at a rural hospital in KwaZulu-Natal, South Africa. South Afr J Epidemiol Infect.2011; Vol 26(1):26-29.

11. I. O. George, B. A. Alex-Hart, A. I. Frank-Briggs. Mortality Pattern in Children: AHospital Based Study in Nigeria. International Journal of Biomedical Science. 2009 Dec15; 5(4):369-72.

12. Rabindra Nath Roy, Saswati Nandy, Prabha Shrivastava, Arindam Chakraborty, Malay Dasgupta, Tapan Kumar Kundu. Mortality Pattern of Hospitalized Children in a Tertiary Care Hospital ofKolkata. Indian J Community Med.2008 July; 33(3): 187-189.

13. Singh M. Hospital-based data on perinatal and neonatal mortality in India. IndianPediatr.1986; 23:579-84.

14. Claeson M, Eduard BR, Tazim M, Pathmanathan I. Reducing child mortality in India in new millennium. Bull WHO. 2000; 78:1193-9. 
15. Park.K. Park's Textbook of Preventive and Social Medicine.20th Edition. Jabalpur (India): M/s BanarasidasBhanot; 2009.

16. Augustine T, Bhatia BD. Early neonatal morbidity and mortality pattern in hospitalized children. Indian J Matern Child Health. 1994 Jan-Mar; 5(1):17-9.

17. ICMR Young Infant Study Group. Age profile of Neonatal Deaths. Indian Paediatrics.2008 Dec 17; 45:991-4.

18. R.D.Wammanda, F.U.Ali. Conditions associated with the risk of death within 24 hours of admission in children in Zaria, Nigeria. Annals of African Medicine 2004; 3:134-137.

19. Marta Botrán Prieto, Jesús López-Herce Cid. Malnutrition in the critically ill Child: The Importance of Enteral Nutrition. Int. J. Environ. Res. Public Health. 2011; Vol 8: 4353-4366; doi: 10.3390/ijerph8114353.

20. Raghvendra Narayan.A study of the pattern of admissions and outcome in a neonatal intensive care unit at high altitude. Sri Lanka Journal of Child Health. 2012; 41(2): 79-81.

21. Ajit Rayamajhi et al.Clinical and predisposing features among children with acute enchepahalitissyndrome in Nepal;aretrospectivestudy.BMCInfect Dis.2011; 11:294.Published online 2011 October 28.doi:10.1186/1471-2334-11-294PMCID: PMC3219745.

\begin{tabular}{|l|l|l|}
\hline Variables & Numbers & Percentage \\
\hline Sex & & \\
Male & 176 & 56.2 \\
Female & 137 & 43.8 \\
\hline Area & & \\
$\quad$ Rural & 195 & 62.3 \\
Urban & 106 & 34.8 \\
Tribal & 012 & 03.9 \\
\hline Birth order* & & \\
1stBorn & 141 & 53.4 \\
2ndBorn & 080 & 30.3 \\
>2nd Born & 043 & 16.3 \\
\hline Season & & \\
Winter & 118 & 37.7 \\
Rainy & 101 & 32.3 \\
Summer & 094 & 30.0 \\
\hline Age Group & & \\
0-7 days & 212 & 67.8 \\
>7 days- 1 month & 021 & 06.7 \\
> 1 month- 1year & 039 & 12.5 \\
> 1 year - 5 years & 030 & 09.6 \\
> 5 year-<12 years & 011 & 03.4 \\
\hline Weight for Age† & & \\
Normal & 057 & 19.5 \\
Underweight & 060 & 20.5 \\
Severely underweight & 175 & 60.0 \\
\hline
\end{tabular}




\begin{tabular}{|l|l|l|}
\hline HospitalStay & 134 & 42.8 \\
Within 24 hrs. & 145 & 46.3 \\
1-3 days & 025 & 08.0 \\
4-7 days & 009 & 02.9 \\
>7 days & & \\
\hline Cause of death & 125 & 35.0 \\
Infection & 101 & 29.0 \\
Birth asphyxia & 076 & 22.0 \\
Prematurity & 021 & 06.0 \\
Congenital & 015 & 04.0 \\
Nutritional & 015 & 04.0 \\
Others & \\
Table 1: Demographic and other outcome information \\
Of deaths occurred during the study Period. \\
\hline
\end{tabular}

*264 death case records mentioned birth order †292 death case records mentioned weight for age at time of admission

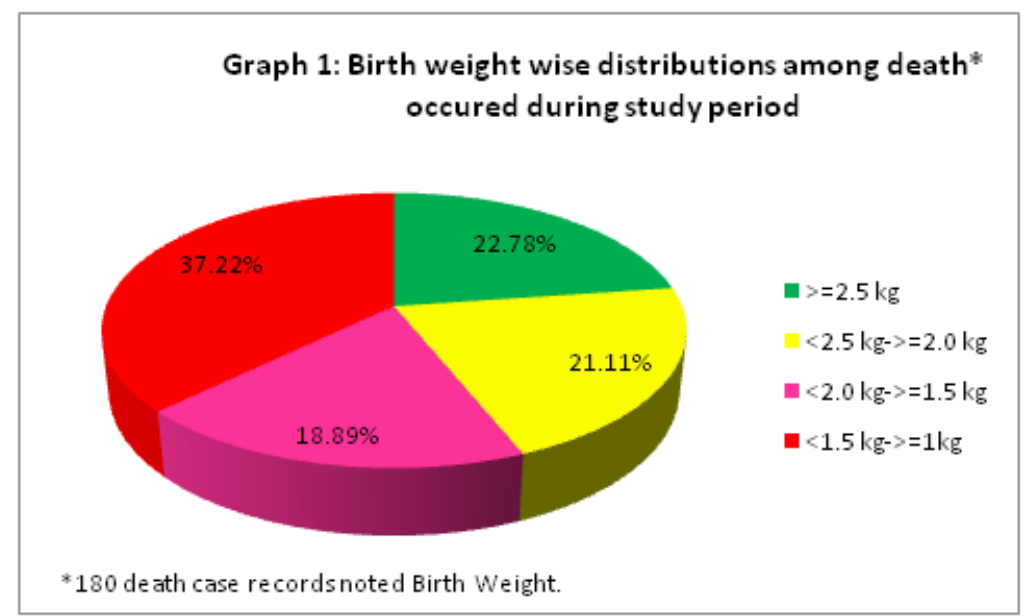




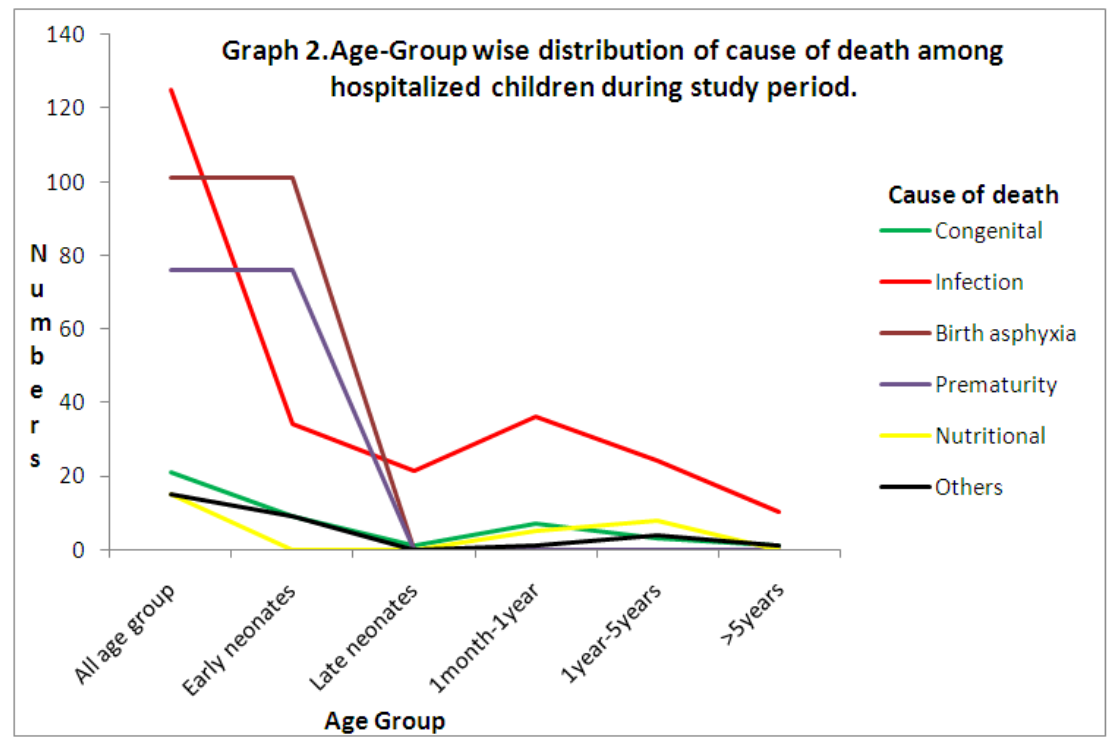

\section{AUTHORS:}

1. Amol R. Patil

2. Anant N. Borde

\section{PARTICULARS OF CONTRIBUTORS:}

1. Assistant Professor, Department of PSM, SBH Government Medical College, Dhule, Maharashtra.

2. Associate Professor, Department of PSM, SBH Government Medical College, Dhule, Maharashtra.

\section{NAME ADDRESS EMAIL ID OF THE} CORRESPONDING AUTHOR:

Dr. Amol R. Patil., 95, Vinod Nagar, Near Netaji Colony, Dhule, Maharashtra.

Email-dramolpatil@yahoo.com

Date of Submission: 17/12/2013.

Date of Peer Review: 18/12/2013.

Date of Acceptance: 27/12/2013.

Date of Publishing: 08/01/2014 